\title{
The Racial Interface: The Computational Origins of Minority Modeling
}

\author{
HUAN HE \\ $\mathrm{PhD}$ candidate, American Studies \& Ethnicity, University of Southern California
}

\begin{abstract}
This article compares two so-called "success stories": Asian/Americans and computers. In the late 1960 s and 1970s, as computers transformed from threatening, wartime machines to user-friendly personal devices, so too did Asian/Americans shift from "yellow peril" to "model minority" citizens. Engaging histories of Asian/America, media art, and information technologies, this article explores the interpenetration of racial and computational forms, logics, and operations within the structures of US liberal capitalism. It examines the discourse surrounding computer scientist Jeffrey Chuan Chu, Japanese American model minorities, and Douglas Engelbart's Graphic User Interface (GUI) alongside a central case study of Nam June Paik's drawing Untitled (TV Face) (1980) and digital artwork Confused Rain (1967). By tracking the emergence of two visual abstractions-the model minority and the computer interface-I theorize "minority modeling" as a racial interface, a representational myth that promotes the dual operations of individualist empowerment and structural obfuscation. While liberal histories of race and computation prop up narratives of social progress and assimilation, Paik's art offers an aesthetics of indeterminacy that emphasizes the irresolvable contradictions linking Asian/American racialization and computational technologies.
\end{abstract}

\section{INTRODUCTION}

On December 13, 1970, the front page of The New York Times featured an article titled "Orientals Find Bias Is Down Sharply in the U.S."1 Using personal narratives to illustrate the newfound "success" of Chinese and Japanese Americans, the article begins with the life story of Jeffrey Chuan Chu:

When J. Chuan Chu came to the United States as a student at the end of World War II from his home in North China, he had trouble finding a place to live. Having an Oriental face, he discovered, was a liability...But $\mathrm{Mr}$. Chu, with an engineering degree from the University of Pennsylvania, has now risen to become a vice president of Honeywell Information Systems. "If you have ability and can adapt to the American way of speaking, dressing, and doing things," Mr. Chu said recently, "then it doesn't matter anymore if you are Chinese." His story reflects a quiet, little noted American success story-the almost total disappearance of discrimination against the 400,000 Chinese and 500,000 Japanese Americans since the end of World War II and their assimilation into the mainstream of American life. ${ }^{2}$ 
For scholars of Asian American studies and critical ethnic studies, this NYT article is a common reference point for the model minority myth. Perhaps the first "face" of the model minority, the Ivy League engineer Chu perpetuates the promise of the American dream, one that upholds individual achievement as a model for racial assimilation. This anecdote depicts the fantasies of an American "success story": the historical recession of discrimination, educational and financial triumph despite racial hardship, and gradual conformity with American culture. This blueprint for minority citizenship programmatically installs the promise of social progress in which the "disappearance of discrimination" functions as the myth's enduring logic. In this telling, not only is Chu's Chineseness no longer a hindrance to becoming American, but the longer US history of anti-Asian discrimination, exploitation, and violence precisely becomes the grounds in which "Americanness" acquires social meaning.

That is, the framing of $\mathrm{Chu}$ as a model minority depends on the past historical injustices experienced by Asian/Americans in order to shore up a culturally compelling narrative of racial progress. In the $N Y T$ article, the invocation of the discrimination faced by "the 400,000 Chinese and 500,000 Japanese Americans since the end of World War II" ${ }^{\prime 3}$ signals the history of yellow peril discourse that has characterized much of Asian racialization in the United States. Yellow peril refers to the well documented plethora of cultural imagery and rhetoric conceiving of Asian bodies as menacing, horde-like, invasive, and inhuman. This racist discourse has been renewed in many historical examples of Asian racialization, such as ideas of "cheap" Chinese railroad labor, the perceived inscrutability of Japanese Americans during World War II, the economic threat of China and Japan as new global world powers, and many other instances of continued anti-Asian feeling, including present discourses surrounding the COVID-19 pandemic. ${ }^{4}$ Yet, despite the persistence of these negative representations of Asian/Americans, the model minority myth claims to resolve the historical structures of discrimination against Asians by facilitating their "total disappearance." Exemplified by the Chinese American engineer, the myth of an Asian/American "success story" encapsulates the operative fantasies of US liberal capitalism, in which the individual subject is purportedly able to overcome histories of racism.

During the 1960s and 1970s, another "model minority" was being mythologized: the computer. In this period, the computer transformed in the larger cultural imagination from a scientific instrument of calculation to an integrated part of social living, from a tool of oppression to an idealized technology of empowerment. The history of the computer marks a narrative of assimilation, in which information technologies have become central to the contemporary mediascape. Made between 1943 and 1945, the first electronic computer was the Electronic Numerical Integrator and Computer (ENIAC). This machine was developed during World War II through collaborative efforts between the Ballistics Research Laboratory, Los Alamos National Laboratory, and the University of Pennsylvania's Moore School of Electrical Engineering. Created for wartime ballistics calculations, the ENIAC was an impressive machinic feat. It was superhuman in its computational capacity and massive in physical scale, taking up an entire laboratory room. Its military roots entrench the computer as an instrument of domination and dehumanization, of power and control. In the 1960s and 1970s, however, new technological visions of the computer began to emerge alongside these wartime imaginaries: the computer itself started to be associated with "liberatory" terms. With a nascent computer industry rising through the likes of Bell Labs, IBM Research, and Silicon Valley startups, the idea of "information" began to take on a different resonance, as information technologies transitioned from war machine to personal device. As N. Katherine Hayles notes, the "great dream and promise of information is that it can be free from the 


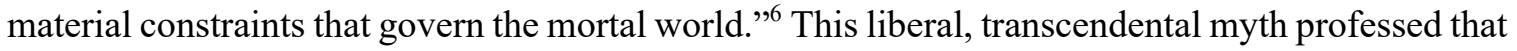
new information technologies were no longer threatening but could be integral and productive components of modern life. What is particularly striking is that J. Chuan Chu was also on the team that designed the ENIAC, the first electronic computer, back in the 1940s. His career as a computer scientist encapsulates two so-called "success stories" in the twentieth century: Asian/Americans and computers.

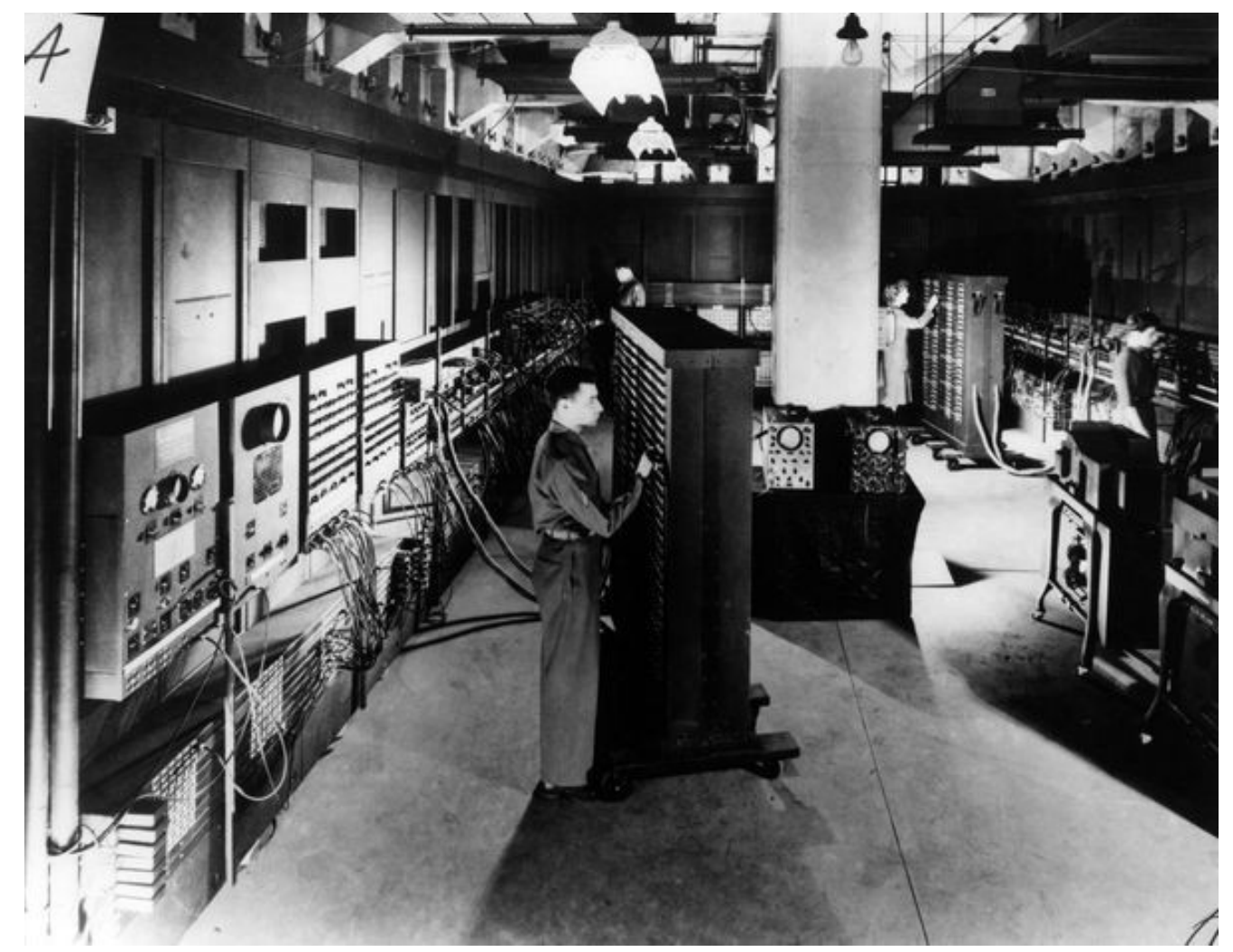

\section{Figure 1. Publicity photo for the Electronic Numerical Integrator and Computer (ENIAC). Image in the public domain.}

This article explores the linked perceptions of Asian/Americans and computers and what this connection reveals about the racial and technological dimensions of US liberal capitalism. Although their dominant perceptions reflect corresponding myths of racial and technological progress, the histories of Asian Americans and computers offer up contradictory beliefs-of otherness and assimilation, of oppression and empowerment, and of alienation and freedom - never fully resolved within the American cultural imaginary. I examine an underlying racial form that links the Asiatic and the computational through technological modalities. Colleen Lye theorizes an "Asiatic racial form," which allows us to think about how the "Asiatic" in cultural production refers "not to persons but to a host of modernity's dehumanizing effects (laboring conditions, group entities, corporations)." In this sense, racial perceptions (such as the hostile "yellow peril" or the assimilable "model minority") are not merely stereotypes; rather, they are visual expressions of an underlying racial form that, I suggest, also take on technological valences. In this article, I utilize the term "minority modeling" to focus less on the figure of the model minority and more on the 
procedure of representation itself, calling "attention to the operations through which race is visualized and coded."

I highlight two key moments in the late 1960s that shifted the perception of race and computation. These flashpoints are the emergence of the "model minority" and the making of the "computer interface," two visual abstractions whose ideological power resides in their ability to reduce race and computation to a skin-deep or screen-deep phenomenon. Produced as a representational "effect," " the model minority and the interface both illustrate how a propensity to work visibly and efficiently shaped the racial and technological imaginaries of US liberal capitalism. Like the computer interface that promised to enable the individual user while hiding the inhuman structures of code, minority modeling promoted a myth of the empowered racial subject who could overcome, and therefore obfuscate, the historical conditions of racism. Thus, the computer's transition from military tool to personal technology is, in part, bolstered by the racial discourse of its time. I suggest that minority modeling functions as a racial interface, rendering race as a screen-level visual effect that obfuscates the sociohistorical structures of its making. In short, minority modeling is a userfriendly design of racial logics, a schema for containing the meaning and power of race within the operations of US liberal capitalism.

This article utilizes the media art archives of Nam June Paik, whose artistic philosophy of "humaniz[ing] technology"10 provides an art-based corollary for investigating the implicit racial logics of the computer's evolution from inhuman machine to user-friendly device. This article explores Paik's writings and artworks, especially his drawing Untitled (TV Face) (1980) and his unrealized digital artwork Confused Rain (1967) created at Bell Labs. While liberal histories of race and computation prop up narratives of social progress and assimilation, Paik's focus on the aesthetics of indeterminacy across these media artworks reveals the corresponding indeterminacies of race and computation, despite their prevailing ideologies of representational empowerment (i.e., minority modeling or the computer interface). If interfaces index the dual operations of empowerment and obfuscation, mediating racial and technological meaning on the visual registers of skin or screen, then Paik's media arts center the deep, irresolvable contradictions at the core of emerging racial-technological imaginaries.

\section{INDETERMINACY OF THE ASIATIC}

Known in the art world for his video and media arts, Asian/American artist Nam June Paik was also a keen theorist of the interface. According to Alexander Galloway, the interface is "not a thing [but] always an effect, always a process of a translation." ${ }^{\prime 11}$ This provocation conceptualizes the interface not as merely as a technical artifact but as a broader aesthetic phenomenon "mediating thresholds of self and world." 12 Although Paik himself never used the terminology of the interface, his experiments in the screen arts intuit this understanding in his artistic practice. For Paik, screens marked the composite arrangements of subjectivity, time, and representation, expressed through different technical media. In his exploration of a particular electronic medium, such as TV, we can see Paik's embrace of poetic metaphor across a range of works including Moon is the Oldest TV (1965), TV Garden (1974), TV Fish (1975), and others. Employing environmental metaphors, Paik decenters the focus on the technological artifact to consider older forms of media, such as the moon. For instance, in Moon is the Oldest TV first displayed at Galeria Bonino in New York City, Paik plays with the registers of temporality. Using twelve vacuum-tubed television sets, Paik uses a magnet to manipulate each TV screen to look like a different phase of the moon, waxing and 
waning. By translating the moon's phases into the televisual screen, Paik's artwork asks the viewer to broaden their conception of mediation beyond the technical artifact and to consider the moon as a cosmic interface, shaping the perceptual field between self and world. In an unpublished note located in Paik's archive, which is housed in the Smithsonian American Art Museum, he draws from Buddhist philosophy to ask a question of art and the moon:

\author{
What is art? \\ Is it the moon? \\ Or \\ The finger-tip, which points to this moon ? $^{13}$
}

If art is not the moon but rather the "finger-tip" that points to the moon, in the way that an interface is not a thing but rather an "effect," then media arts offer a method for exposing the underlying logics that configure the perceptual fields of the technological. For Paik, media art can attune to the processes of perception in contemporary screen cultures, like a revealing "finger-tip" or a familiar computer cursor.

Scholarship in media art history has considered the intermedial dimensions of Paik's artistic work, in which Paik's experimentations across a range of technological media is one of his greatest contributions. According to Gregory Zinman, for instance, Paik has "consistently explored how concepts or practices developed in one media form would find expression in another."14 Paik's intermedial approach did not subscribe to any fixed notion of media specificity in order to emphasize the logics, energies, and desires that shuttle between different forms, technological or otherwise. It is precisely this artistic intermediality that is useful for the historical study of technologies, as it helps chart unexpected links for understanding the digital present. Paik exemplifies what Jussi Parrika has called "media-archaeological creative practices," referring to the "use [of] aesthetic methods as epistemological investigations-formations of knowledge ... about our technical world around us that is often structured as 'imperceptible." "15 Paik's artistic practice reveals media technologies themselves to be indeterminate, merely condensing in time and space as an effect of social, cultural, and technical forces.

Besides the environmental metaphors employed by Paik's TV-based media art, one important analogy for his screen-based experiments was the concept of race. In 1980, Paik produced a littleknown drawing referred to as Untitled (TV Face). Deviating from his usual practice of using technological screens as canvas or material, $T V$ Face is a hand-drawn depiction of a screen on a sheet of white paper. Blue pastel scribbles and heavy black coloring mix, giving an impression of an abstract screen filled with static. This paper drawing of a staticky screen thus aligns with Paik's intermedial ethos of exploring the representation production and rupture of the screen itself. Overlaid are strips of yellowed tape that give the impression of a caricatured "Asian" face: a slanted eye and buckteeth. Resembling the racist imagery applied to Chinese and Japanese individuals, $T V$ Face harkens back to the "threatening" portrayal of Asians as "yellow peril," a racist representation that haunts the twentieth and twenty-first centuries. 


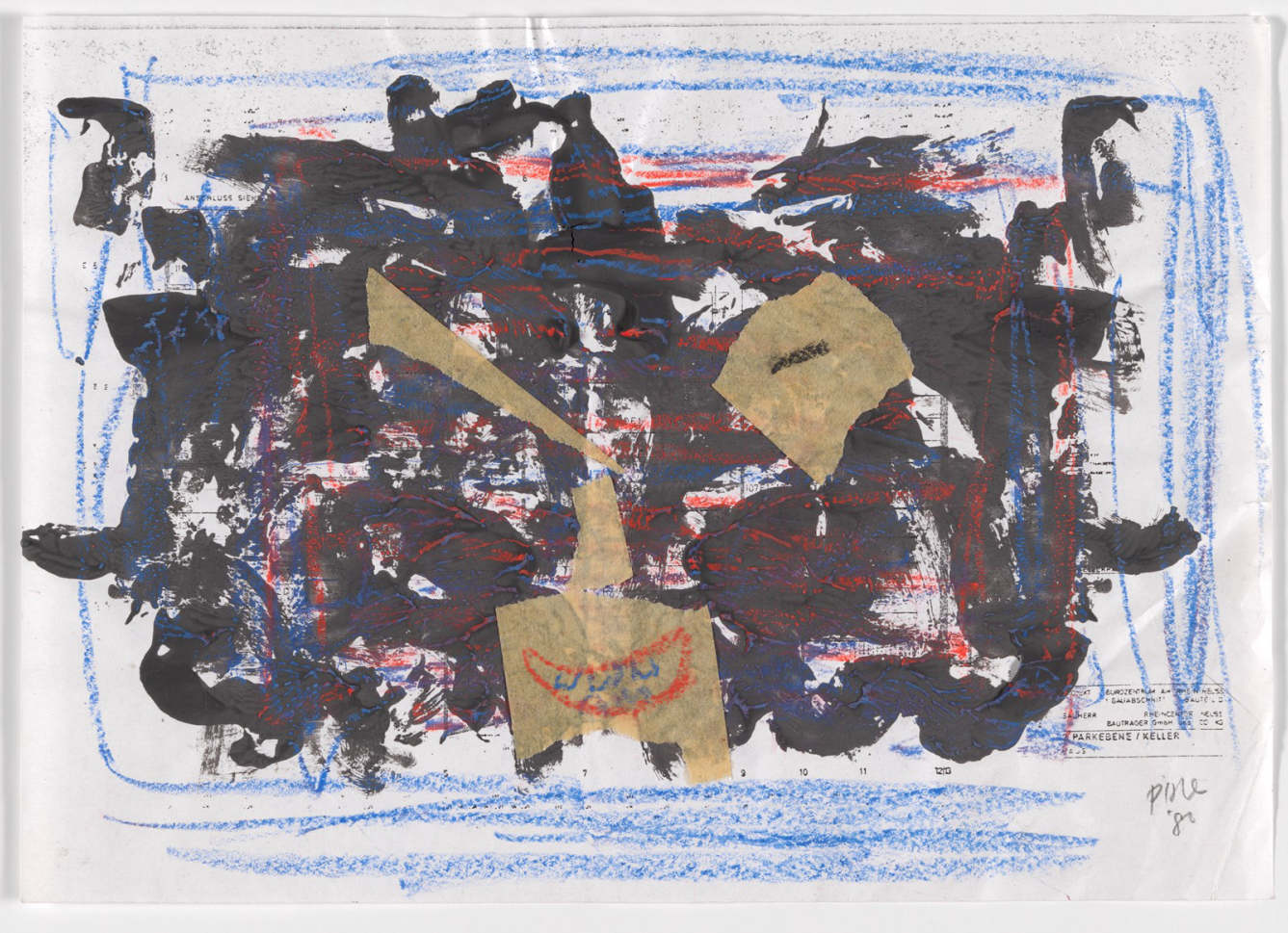

\section{Figure 2. Nam June Paik's Untitled (TV Face), 1980. Collage, pastel, and tape on printed paper. San Francisco Museum of Modern Art, Gift of the Hakuta family. (c) Estate of Nam June Paik. Photograph: Don Ross.}

Conflating an aesthetic of yellow peril with the static of a screen, TV Face uses a depiction of technological glitching to remediate the historical formation of Asiatic fear. Representationally, yellow peril is a visual abstraction that refers to different Asian-identified subjects, such as Chinese migrants and Japanese citizens, in an atmosphere of collective national fear and hatred. Its formal rendering as a menacing, Asiatic face reflects the racist sentiment $\mathrm{Chu}$ alluded to in the opening NYT article: "[h]aving an Oriental face... was a liability." ${ }^{16}$ In the case of TV Face, the liability is cast as a technical one, alluding to glitching, visual noise, and malfunction. Within his oeuvre, screens were the technological equivalent of a face. In fact, Paik was quite fascinated with imposing faces on screens, including his large-scale works such as Li Tai Po (1987), as well as smaller pieces like Smiling Face (1986). Paik would sometimes distort his own face on the screen or even pose for photographs with TV sets by playfully inserting his face into the screen. What unifies Paik's TV Face and Chu's commentary on the "Oriental face" is a mutual recognition that the face is a representational abstraction, figuratively marking a deeper historical or technological process that gives the face social meaning. Illustrative of minority modeling's logic, Chu's "Oriental face" is something to obscure, supposedly evidencing the "almost total disappearance of discrimination." The NYT article touts Chu's "engineering degree from the University of Pennsylvania" as the key to overcoming his racial "liability," ultimately allowing him to "[rise] to become the vice president of Honeywell Information Systems." The article frames engineering as an empowering vehicle for Chu's social mobility, as the key to minimizing the liability of his racialized face. In contrast, Paik's TV Face presents a much more ambivalent expression of the "Oriental face," one that does not fit 
into a myth of racial progress. Since Paik uses a non-time-based medium, TV Face does not clarify whether the yellow peril figuration of an "Oriental face" is becoming more visible or disappearing into the static. Rather, the artwork lingers in a representational indeterminacy that characterizes the status of the Asian in the American imagination.

If minority modeling promised that racial subjects could overcome their historical "liability" and obscure the relevance of race in an era that supposedly saw the "almost total disappearance of discrimination," ${ }^{17}$ then Paik's TV Face challenges the visual clarity of this myth of modeling by embracing an aesthetic of indeterminacy. Paik's fascination with indeterminacy-the forces of chance, contingency, and disorder - draws from cybernetics and information theory, especially the work of Norbert Weiner. Paik was particularly interested in the idea of feedback, or what Weiner would describe as "the property of being able to adjust future conduct by past performance." 18 Emerging from wartime statistics research of the 1940s, feedback was foundational to cybernetic theory. The term referred to the ability to predict an entity's behavior and actions and proved useful for wartime ballistics combat. Shaping much of the early decades of the information era, the idea of feedback became embedded in media technologies and their technical operations. Orit Halpern notes that feedback was a "nascent form of interactivity," creating a technical episteme of input and output. ${ }^{19}$ Feedback was about prediction, control, and efficiency, a way to quickly determine meaning from an external world awash in chaos, to glean information from noise. For Paik, indeterminacy as an aesthetic concept challenged the information clarity of feedback systems within media technologies, using technical glitching to complicate the assuredness of screen-based representation. Paik's work participated in the larger embrace of feedback by artists, activists, and theorists, such as those associated with the publication Radical Software in the 1970s. ${ }^{20}$

Indeterminacy provided a framework for understanding the contradictions of Asian racialization. In an unpublished essay meditating on feedback, Paik suggests that "feedback techniques run in many layers of symbolism," ${ }^{21}$ a claim that resonates with Paik's consistent use of analogy to situate technological ideas and artifacts within social and political reality. As a media artist invested in social critique, Paik describes his aesthetic practice as a historiographical one: "My aim is not to find out the 'truth,' what actually happened, but just to find out what was fed to people as the 'truth,' which was to form the consensus and influence the history." ${ }^{22}$ Attuned to Steve Anderson's assertion that "all history is really historiography," ${ }^{23}$ Paik was equally invested in unsettling the perception of both technological and social forms, both as a product of historical conditions. Paik was uniquely aware of the indeterminacy of the Asiatic in the American cultural imagination. During the Cold War, Paik notes in an untitled essay on feedback how "China has turned suddenly from No. 1 friend in Asia to No. 1 enemy in the world...Input became output. Plus became minus." ${ }^{24}$ Using the technical rhetoric of input and output, Paik suggests that the Asiatic racial form, signified by the geopolitical entity "China," produces contradictory representations under different historical circumstances. At times positive ("friend") and other times negative ("enemy"), the Asiatic demonstrates how racial meaning cannot be fixed as truth but rather as indeterminate, and as suggested by Colleen Lye, always tethered to the "international context in which American race relations take shape. ${ }^{25}$ By attuning to the ambiguity of racial perception, TV Face invokes the question of how racial meaning becomes fixed as "truth" within history, akin to Paik's critical attention to screen-based mediation.

As an aesthetic method, Paik's media art reveals how racial and technological formations converge in corresponding ways. Paik's fascination with how social meaning achieves the power of "truth" 
in contemporary information technology cultures extends to a consideration of Asian racialization. Like the magnets or the Paik-Abe synthesizer ${ }^{26}$ he uses to manipulate television sets and video signals, Paik suggests that perceptions of the Asiatic are subject to distortion by historical forces.

By exposing how visual effects accumulate power as "truth," Paik's artistic inquiries offer a case study for my theorization of the racial interface, as it pertains to the history of computation. In her formulation of "race and/as technology," Wendy Hui Kyong Chun disrupts any settled notion of race as a cultural or biological "truth" in order to attend to the mediating function of race, a way for "linking what is visible to what is invisible." 27 Chun reminds us that race is a complex visual abstraction, and its moments of representational clarity should always be treated with suspicion. By attending to the inner workings of representation, the underlying code that historically produces the effect of "truth," Chun suggests that race, as a dominant technology of power, cognitively organizes and maps social relations across time and space. Her framework proves useful for investigating the late 1960s, when the idea of Asian/Americans as "model minorities" began to emerge as a sociological "truth" during a pivotal decade of racial reckoning. Despite being perceived in previous decades as "yellow peril," foreign and threatening to Euro-American ways of life, Asians/Americans became idealized in the cultural consciousness as "model" American minorities. Model minorities, however, also exemplify a process of minority modeling, in which Asian/Americans were not only celebrated but were promoted as a model of racial subjectivity for other racial groups to emulate. Building on Chun's assertion of race "and/as" technology, I examine how the concept of modeling links seemingly disparate forms of computation and culture that were coevolving in the shadow of US liberal capitalism.

Through tracking Paik's aesthetics of indeterminacy, I complicate art historical accounts of his desire to "humanize technology." Scholars often frame Paik as a "visionary" whose art anticipated the successful integration of new information technologies into human society, such as the introduction of the World Wide Web of the 1990s. For instance, Michelle Yan writes, "As early as the 1960s the artist Nam June Paik challenged his contemporaries to imagine a future where today's innovations might exist." 28 By rendering Paik as a prophet of new media environments, these descriptions situate his philosophy of humanizing technology within a dominant history of digital and information technologies, as they transitioned into ubiquitous, personal devices and companions. I suggest that foundational to Paik's aim to humanize technology were the aesthetics of indeterminacy, a recognition of the contradictions within an emerging information technology culture that could not be fully reconciled through user-friendly commercialization. His media art show that to humanize technology was not to resolve these contradictions but to imagine ways to live with and alongside them. Excavating the indeterminate and the irresolvable, Paik's arttechnological experiments were not necessarily prophetic but diagnostic, pointing to the contradictions at the core of dominant myths of social and technological progress.

\section{MODEL MINORITIES AND MODEL COMPUTERS}

This section develops my concept of the racial interface by examining how perceptions of Asian/Americans as model minorities emerged alongside the development of the computer interface. At their core, both models are powerful visual abstractions that acquire the mythological effect of social or technological "truth" by reducing complex historical formulations of race and computation into usable ideas. Like the interface that provides a sense of user agency, minority modeling creates the belief that an individual racial subject could overcome historical and structural 
conditions. Moreover, this effect of empowerment gains ideological power because it circulates as a lived promise, thus obfuscating the social forces of its making. Racial discourses, such as minority modeling, fortified the computer's transition from wartime machine to personal device. Reciprocally, information technologies covertly participate in what Jodi Melamed describes as the "trick of racialization," 29 containing racial meaning to an aesthetic dimension of cultural representation. Computer history, then, encapsulates a genealogy of US liberal capitalism.

As mentioned previously, minority modeling contains two computational ideologies that work in tandem to bolster US liberal capitalism's operations: individualist empowerment and structural obfuscation. Thus, one problematic function of minority modeling is that it valorizes the achievements of the individual, or individual group, in order to elide the ongoing structural oppression of other marginalized populations. Scholars like Ellen Wu have demonstrated how the model minority myth is a tool of whiteness, in which Asian/American success is used to devalue demands for racial and economic justice by Black, Latinx, and other disenfranchised groups. ${ }^{30}$ The model minority myth is a racial abstraction that refers to a range of Asian/American experiences, including Japanese and Chinese Americans, as well as select groups of non-Asian/American minorities. Under its logic, the capacity to work productively and efficiently is the rubric for obtaining social inclusion into the nation-state. Minority groups with a notable history of exploitation, disenfranchisement, and violence become exemplars for this capacity to work, precisely because the narrative of perseverance through oppression gives potency to the meaning of "hard work" while effacing the continuity of structural racism. William Petersons' New York Times article titled "Success Story, Japanese-American Style" (1966) is often regarded as the first general account of the model minority myth. Instead of focusing on a single individual like Chu, Peterson emphasizes the experience of Japanese Americans as an ethnic group to espouse a minority "success story":

The history of Japanese Americans, however, challenges every such generalization about ethnic minorities, and for this reason alone deserves far more attention than it has been given. Barely more than 20 years after the end of the wartime camps, this is a minority that has risen above even prejudiced criticism. By any criterion of good citizenship that we choose, the Japanese Americans are better than any other group in our society, including native-born whites. They have established this remarkable record, moreover, by their own almost totally unaided effort. Every attempt to hamper their progress resulted only in enhancing their determination to succeed. ${ }^{31}$

Peterson offers a narrative of racial progress from the perspective of the model minority myth. In this view, freedom from historical violence supposedly depends on self-reliance and selfsufficiency, in which sheer determination is enough to overcome historical oppression.

The model minority myth emerged in the mid-to-late 1960s during a period of rapid technological developments. With the establishment of Silicon Valley and advances in hardware and software technologies, the computer became a cultural artifact that reflected the hopes and fears of a new information age. As corporations such as Fairchild Semiconductor, IBM, and Bell Laboratories hoped to commercialize new computational technologies, the computer expanded beyond its role as an instrument of military research. Within the social imagination, the computer's fast and efficient capabilities enshrined it as a transformational technology that could better human life with remarkable speed. In 1965, Gordon Moore, the research director of Fairchild Semiconductor, 
posited his law on accelerated information processing in the computer age. According to this now famous "Moore's Law," computing would exponentially increase in power and decrease in cost every two years, due to advancements in integrated circuits and microprocessors. ${ }^{32}$ For the digital electronics industry in the $1960 \mathrm{~s}$ and $1970 \mathrm{~s}$, when silicon transistors were crammed into microchips, Moore's Law served as a "golden rule" and fueled technological visions of innovation. Computers themselves would become more efficient and more powerful, as processing capabilities entered new horizons with microelectronics. This became the dominant narrative of the digital revolution, a story of technological determinism in which computers "naturally" became an integral part of the social landscape.

But how did the computer become assimilated into the social imagination? The answer lies, partially, in a history of design thinking, a way to profoundly frame how we understand computational tools, even as their processing capabilities became more powerful at the same time as they were becoming more invisible. This is the story of the interface, the result of many experiments with human-machine interactivity. According to Chun, the commercial history of interface is "widely assumed to have transformed the computer from a command-based instrument of torture to a user-friendly medium of empowerment." 33 Yet, as Alexander Galloway reminds us, interfaces are an aesthetic effect of mediation, ${ }^{34}$ obfuscating the machinic operations of computation while producing an empowering representation of its technical functions. Although interfaces also have origins in military research, the interface's technological power is often associated with user agency. Even though they consistently fail their users, interfaces and the visual power they wield allow computation to be a non-threatening and integrated part of the social landscape.

It is fitting that in the late $1960 \mathrm{~s}$, the period in which journalists and sociologists coined the term "model minority," advancements in computation introduced the graphic user interface, or GUI. Although the GUI has links to midcentury radar systems such the Semi-Automatic Ground Environment (SAGE), ${ }^{35}$ the user interface in its most familiar form can be traced to the influential work of Douglas Engelbart. ${ }^{36}$ In the 1960s, he created a new text-based hyperlink program called the "oN-Line System," or NLS, inaugurating "a new dreamscape for what computing was to become: the mouse, the teleconference, email, the windowed user interface, the hyperlink, the internet." ${ }^{, 37}$ NLS was developed in Engelbart's Augmentation Research Center at the Stanford Research institute. In 1968, he presented this new system in a 90-minute demonstration famously known as the "The Mother of All Demos." 38 Engelbart showcased how he could navigate hypertexts, graphics, folder systems, and windows through the easy control of a cursor to an audience awe-struck by Engelbart's omniscient command. The cursor provided a way to navigate the visual/spatial composition and logic provided by a user-oriented screen. In the early 1970s, Engelbart's NLS team migrated to Xerox PARC (currently known just as PARC, or the Palo Alto Research Center) and helped to develop the earliest personal computer built with a GUI in mind. The interface employed visual models and graphics - visible, navigable, and interactive - in order to calibrate the technical imaginary of the computer, rendering the computer as something nonthreatening and workable.

Made possible by a GUI, a user-friendly computer was an important part of Engelbart's larger technological vision for "bootstrapping," a computational term with ideological resonances beyond computer history. The term "bootstrapping" derives from liberal discourses, in which the logic for social progress is dependent on an individual's capacity for hard work and perseverance. In the nineteenth century, bootstrapping referred to the mentality of "pulling oneself up by one's 
bootstraps," a task deemed quite impossible to achieve. However, by the twentieth century, its connotation had shifted to the opposite meaning: to achieve the near-impossible without the aid of others. In its contemporary meaning, bootstrapping has strong associations with the model minority myth. Conceived as the exemplar of model minority logic, Asian/Americans' propensity for overcoming racial discrimination (such as Japanese internment and anti-Chinese exclusion) becomes a rubric for US minority life more broadly. Bootstrapping functions as an aspirational ideology of individual empowerment that obfuscates deep systemic racial infrastructures. Not only does it suggest that progress is something specific to an individual or particular group, but it also installs the rubric of efficiency as the mode for escaping race-based disenfranchisement. Returning to Peterson's New York Times article on the Japanese American model minority, one can find the resonance of a self-enclosed capacity for overcoming racism: "They have established this remarkable record, moreover, by their own almost totally unaided effort. Every attempt to hamper their progress resulted only in enhancing their determination to succeed." 39 Through a bootstrapping logic, the capacity for social progress appears to be dependent on, rather than despite, historical discrimination and violence.

In similar ways to bootstrapping as a racial ideology, bootstrapping in computation refers to a vision of software development that aspires to make complex programming more efficient and legible for a human user. Thus, bootstrapping indexes the process of humanizing computation, or assimilating code into greater levels of human usability. In the most general terms, bootstrapping is what allows the separation of code and machine. Computers are comprised of machine code, or the binary digits 0 and 1, that corresponds most closely to the hardware processes. Stored in the actual hardware of the computer, machine code is machine-dependent and is the most technical and inhuman type of programming language. Because of the isolated nature of machine code, higher levels of programming languages are needed to make computers more usable, accessible, and humanized for software developers. For this reason, bootstrapping refers to the process by which programmers can produce more complex forms of code that scale beyond the individual machine. Through assemblers and compiler languages, software engineers can develop higher-level programming languages that make machine language palatable and more "human," or closer to semantic and linguistic systems. From an accessibility perspective, code that is more developer-friendly allows for more complex, faster programming environments to emerge, which results in media ecosystems unified by software. However, as Wendy Hui Kyong Chun reminds us, the higher-level versions of programming languages fortify the technological myth of software as an invisible and intangible "thing" beyond the screen, promising to empower the programmer or user while the code disappears from view. ${ }^{40}$ Bootstrapping, then, is a process of producing not only more complex code environments but also more "human" forms of code. It installs an imaginary of human-machine relations: that one primary aim of technological innovation is to make computers work for us in visible and efficient ways.

According to Thierry Bardini, Engelbart greatly influenced the modern digital age by developing bootstrapping as a technological ideology. ${ }^{41}$ Engelbart envisioned bootstrapping as an iterative and collaborative environment not only for increasing research productivity but also for increasing the capacity for productivity. Drawing from cybernetic concepts of feedback, Engelbart believed that the computer as a new information technology could play an integral role in advancing human knowledge and research exponentially if it could optimize organizational efficiency on a broader scale. Rather than understanding computers as autonomous entities, ${ }^{42}$ Engelbart believed that these new technologies could work in tandem with users to enhance and extend user capabilities. ${ }^{43}$ Within 
this vision of bootstrapping, the interface mediated human-machine interactions and optimized computational efficiency. That is, by reducing the need to understand how computers work as machines, users could maximize their productivity and capacity. Separating the inhuman dimensions of machine code from the user-friendly graphical schema, the interface presented a fiction of subjective agency vis-à-vis the "humanized" experience of computation.

Engelbart's embrace of cybernetic concepts influenced his view of computation as a type of machine-based augmentation of human society, in which feedback allowed computation to become a productive component of an emerging information technology ecosystem. For Engelbart, feedback enabled the seamless optimization of human-computer interaction, a technological ideology facilitated by the visual power of the interface. Feedback privileged a narrative of technological efficiency, in which past error and insights would play a role in the ability of the computer, or society at large, to recursively improve. What Engelbart imagined was a progressoriented teleology of computational power that corresponded with the fundamental tenets of US liberal capitalism. That is, the past could not only be overcome and obfuscated; it also played a direct role in making the logics of efficiency and productivity socially meaningful in the technological realm. Engelbart's vision was a computational corollary to Peterson's framing of the "criterion for good citizenship." Alluding to the historical discrimination faced by Japanese Americans, Peterson asserts that "every attempt to hamper their progress resulted only in enhancing their determination to succeed." 44 Peterson's valorization of Japanese Americans as model minorities was based not merely on the social success that they had achieved but also on their ability to turn historical discrimination into an enhanced determination, a type of recursive teleology for modeling social mobility. Together, Peterson and Engelbart illustrate the interpenetration of computational and racial discourse, facilitated by a recursive and teleological framing of feedback.

Tara McPherson has argued that there is something formally particular to digital computation that works to "cordon off race and to contain it," 45 in that it is difficult to identify what is racial about computing. In other words, the technical history of computers may appear to have very little, if anything, to do with race and racialization. This process of effacement is not only a paradigmatic logic of computational structures but also an integral function of US liberal capitalism in the midtwentieth century. In this sense, effacement lodges racial logics and operations beneath perceptible view. What I have suggested is that our computation imaginaries and racial mythologies, such as Asian/American minority modeling, are mutually reinforcing in an era of both technological and social transformations in the United States. Like the logic of minority modeling, which valorized individualist empowerment while obfuscating historical structures of racialization, the interface encapsulated these dreams of how computers, as productive machines, could be seamlessly assimilated into the mediascape of new information technologies. In other words, by promoting the perceived ability to "[rise] above...prejudiced criticism" ${ }^{46}$ through the empowered individual, minority modeling does not challenge the structural source of US racial discrimination but rather emphasizes ways to make discrimination itself disappear from view, serving as another technology of cordoning off race. Minority modeling emerged in the late 1960s when US and transnational uprisings began to collectively challenge structural racism, colonialism, and disenfranchisement. ${ }^{47}$ As an effective technology of managing the explosion of social meaning, complexities, and energies, minority modeling functioned as a racial-technological schema for designing a userfriendly experience of race. By rendering race into a graphic phenomenon, as merely skin-deep or screen-deep, minority modeling as a racial interface served to quell deeper structural critique and relational modes of solidarity. 
As I have suggested, the rise of the computer as a model technology tracks closely with the emergence of Asian/Americans as a model minority. This overlap is, in part, due to the occupational concentration of Asian/Americans in the science, technology, engineering, and mathematics (STEM) fields. In 1968, the Hart-Cellar Act of 1965 went into effect and abolished the quota system restricting immigration based on national origin. This reform caused an influx of new Asian migrants to the United States (primarily of East Asian and South Asian descent) as a skilled and technical labor force. In 1964, only 14 percent of immigrants in the scientific and technical fields were of Asian ancestry, while in 1970, the total rose dramatically to 62 percent. ${ }^{48}$ The historical tendency towards STEM fields became a vehicle in which Asian/Americans were further concretized as minority models. Thus, minority modeling, as it pertains to Asian/Americans, is not only a racial form but also a scientific-technological one. As such, technical laboratories also participated as a site of racialization, in which the ideologies of "objectivity" and "universalism" often associated with the sciences corroborated the minority model mythos of race's irrelevance. The 1968 Asian/American STEM boom also echoed previous attempts to recruit elite science and technology students and researchers from Asian nations. For instance, Chu himself immigrated from China to the United States during World War II when Japan invaded Shanghai in $1940 .{ }^{49}$ Thus, the impact of the Hart-Cellar Act on immigration demographics can be traced back to earlier efforts of US-East Asia scholar-researcher exchange, such as the Boxer Indemnity Scholarship established in 1909. The Boxer Indemnity Scholarship, which was offered during the era of Chinese Exclusion (1882-1943), marks the selection of elite Chinese/American researchers over disenfranchised laborers. Across the twentieth century, scientific-technological development has facilitated the model-making effects of Asian/American racialization in the US social landscape. ${ }^{50}$

\section{ASIAN/AMERICAN DIGITAL ARTS AND THE LOGIC OF (IN)EFFICIENCY}

Although Paik himself immigrated to the US before the 1965 Hart-Cellar Act, the development of his art practice coincided with the forceful emergence of this association between Asians and technology that occurred in the late 1960s. As one of the canonical artists associated with the arttechnology projects in this time, Paik's racial identity is still mostly ignored or only briefly mentioned by most art critics. ${ }^{51}$ What I am suggesting here is that the STEM-driven economic conditions inform Paik's racialization and are not simply background historical context. Rather, they shape how we read —or don't read — the racial dimensions of Paik's media art. My intervention here is partially evidentiary, as I aim to question what counts as evidence for racial inquiries within media art archives. Simply identifying Paik's overt discussions of race would cordon off the relevance of race to its explicit mention and thus overlook its underlying logics, processes, and operations, similar to the way computational technologies "cordon[ed] off race." 52 Instead, I return to Paik's media archive to track the racial-technological modalities of efficiency and how they impact his media art investigations. If the power of US liberal capitalism lies partially in its investment in the representational model, akin to what Chun might term "the persistence of visual knowledge" ${ }^{, 3}$ in reference to the age of software, then media art archives can be crucial sites for revealing how artists negotiate these ideas in both realized and unrealized projects. Attuned to the dynamics of interfaces and screens, Paik's archive contains moments in which the processes of artmaking, technology-making, and race-making collide.

As Gregory Zinman highlights in "Nam June Paik's Etude 1 and the Indeterminate Origins of Digital Media Art," Paik was one of the first artists to tinker with computational media for the purposes of artistic expression..$^{54}$ In 1967 and 1968, Paik held an informal residency at Bell 
Laboratories to experiment with the programming language FORTRAN. ${ }^{55}$ Owned by AT\&T and Western Electric Company, Bell Labs was an influential American information and communications research institution. ${ }^{56}$ During the late $1960 \mathrm{~s}$, Bell Labs began to explore ways to make the computer more "usable" for non-scientists and non-engineers by exploring how visual graphics could enhance human-computer interactivity. For this task, they invited artists who worked in a variety of mediums, including painting, poetry, music, visual art, and performance. This collaboration allowed artists to experiment with how the computer might expand the aesthetic, sensorial, and perceptual boundaries of their art. On the other hand, artistic experimentation promised to offer new creative insights for Bell Lab's research projects. ${ }^{57}$ In the words of Paik, "computerized video experiments derived from the unorthodox instinct of an artist will surely bring forth some unusual results in the research of pure science and applied technology." 58 As a whole, these invited artist residencies played a role in information technology's transition into the consumer sphere by incorporating the humanizing impulse of art into the tech laboratory. Paik's brief residency at Bell Labs marked another early experiment with the computer interface, occurring in the same years as Engelbart's GUI developments on the West Coast.

While other early computer artists at Bell Labs such as A. Michael Nolls and Kenneth C. Knowlton worked to demonstrate the usability of computer graphics for animating film, video, and other visual forms, Paik's digital art experiments exposed the indeterminacy at the core of computational media. Initiating a series of unrealized and largely forgotten artistic experiments, Paik was interested in creating machine-generated art built from the randomness of programming code. During his residency, Paik experimented with three digital artworks: Digital Experiment in Bell Labs (1967-1968), Etude 1 (unrealized), and Confused Rain (unrealized). Each of these projects used the programming language FORTRAN to generate a time-based visual output while simultaneously revealing the difficulty of the computer medium. Because these pieces are unrealized, which may have been Paik's intention all along, they demonstrate a vision of the computer as unusable for a non-engineer. Working against racial-technological modalities of visibility and efficiency idealized by computational imaginaries, Confused Rain highlights their indeterminacies in Paik's artistic explorations at Bell Labs.

Paik created Confused Rain, a piece depicting a disarrayed assemblage of letters from the word "confuse" marked in black ink on white paper. The letters descend the page in random clumps of C-O-N-F-U-S-E, resembling the fall of textual rain down a blank canvas. ${ }^{59}$ William Kaizen has likened this illegible graphic output to concrete poetry, similar to the work of Paik's fellow FLUXUS artists such as Jackson Mac Low and Alison Knowles. ${ }^{60}$ Confused Rain uses blank space, textual play, and aesthetic difficulty to shroud the art object in a veil of illegibility. The signifier, "confuse," broken up into its individual letters quite literally connects the graphic output to its programmatic making, in which the represented word "confuse" also describes the process of representing. Exposing the "lack of common sense" ${ }^{61}$ embedded within code-based operations, Paik highlights the indeterminacy of computational media while refusing any interpretive refuge on the level of the screen. When attempting to make sense of his Confused Rain piece, the viewer is confronted with the random assortment of letters, a type of "page not found" artifact that does not disclose any artistic meaning based on screen content. Even Paik's invocation of rain, often associated with generation, productivity, and growth, is counterintuitively associated with degeneration and disruption of representational meaning. Rather than showing how computational media could be a model technology for a new frontier of artistic exploration, Paik exposed the unmodel characteristics of code. Demonstrating a failed interface, in which artistic output was not 
rendered visible, predictable, or efficient, Confused Rain encapsulates a moment in the history of digital art that is at odds with the computational imaginaries of usability in the late 1960s.

By revealing the unseen operations of graphic representation, Confused Rain stages familiar debates relevant to Asian/American cultural analysis within a computational environment. Kandice Chuh has critiqued the discourse of "aboutness" (i.e. what is Asian/American about this art?), which, for Chuh, encodes relations to labor and time. She writes, "Aboutness is an instrumental analytic; it enables a quick determination of relevance that is also a determination of timeworthiness, as in, is this lecture or book worth my time?"62 The discourse of "aboutness" functions as a technology of efficiency, described by Chuh as an appealing "mechanism that helps to sortand to sort quickly - that which is important and 'relevant' from the rest." 63 By promoting the logic of efficiency via categorization, "aboutness" is an epistemology of the age of information abundance. To ask what a thing is "about" functions as an unevenly applied question across modern regimes of knowledge production. Chuh reminds us that how, when, and where race signifies is often conditioned by the selective containing of racial knowledges within institutions. In this sense, her analysis of "aboutness" resonates with Tara McPherson's specific concerns regarding information technological formations, a process that "partitions race off from the specificity of [its] media forms." 64

Thus, I consider Confused Rain to be an artwork at the intersection of race and computation because it shores up the logic of efficiency, or lack thereof. Unlike Engelbart's successful GUI and demonstration of the oN-Line system, the inefficiency and slowness of FORTRAN played a role in Paik's abandonment of computational media as a platform for artistic expression. In the early 1990s, Paik reflected on his frustrating experience at Bell Labs:

I thought digital technology, at its enfance [sic], was too slow for me. It took three months to run my first computer generated movie BUG frEE. I thought, what if I work for a year for a program and if the result does not please me??? . . However the good old analogue way the real time thing I could quickly modify, hijack and crush . . . and rise again . . . [I]t was more human. ${ }^{65}$

Paik's struggle with early programming languages demonstrated how channeling artistic intent through FORTRAN punched cards was a laborious task. These punched cards encoded data through a series of input holes in 72 columns. Any error in the physical punching of holes could result in re-typing the entire card. Decks of punched cards constituted a "program" or a set of programs that could be used to execute a computational operation. Because of this error-prone process, a computer programmer would often utilize coding sheets to sketch out the intended function of each portion of punched card code. However, even with these steps, code often contained "bugs" that broke the program. For Paik, this process of expressing an artistic vision through FORTRAN was "too slow" and was difficult to keep bug free. In his reflection on his artist residency at Bell Labs, Paik foregrounds the terms of speed and efficiency as his primary issues with FORTRAN. Such a frustration led him to desire a way to "rise again," a puzzling phrase that shares language with both the description of J. Chuan Chu (who had "risen to become a vice president of Honeywell Information Systems"66) and Peterson's Japanese Americans ("a minority that ha[d] risen above even prejudiced criticism" ${ }^{67}$ ). Paik's comments on the desire to overcome the programming limitations of FORTRAN fortify a "more human"68 technology as ideal. Yet despite Paik's wish, Confused Rain remains a stubborn testament to the computer's "lack of 
common sense" and failure to deliver artistic meaning. Its formalization of computation's indeterminacy, signified by the meaninglessness of the word "confused," exceeded the rubric of the human that valorized computational and racial capacity. By foregrounding its internal nonsensical operations and proclivity for error, Confused Rain suggests that the desire for a "more human" computer was, ultimately, a manufactured myth of the late 1960s and 70s based on the logic of efficiency. The designation of the "more human" might even be understood as the ultimate interface, in which the dream of assimilation promises to resolve the historical production of social difference, whether technological or racial.

In conclusion, by engaging Paik's digital arts archive as a case study, this article has demonstrated the uses of racial critique within liberal capitalist histories that obfuscate its racial content. Even without a visible ethnic subject, the computational concerns laid bare by Confused Rain strongly resonate with the logic of Asian/American racial formation. Reflecting its American capitalist values of individual empowerment, minority modeling shows that liberalism's terms of efficiency and representation are bound to the expansion of computational and digital power in the 1960s and 70s. Yet, Confused Rain does not fit into the user-friendly desire of technological assimilation, marking the computer's transition from wartime machine to personal device. The illegible desires of Confused Rain, then, index the need to trace critical genealogies of "humanizing technology" that exceed dominant narratives of racial or technological progress and development. If, as Neda Atanasoski and Kalindi Vora contend, "humanity as an aspirational figuration" functions as an "alibi of present-day racial capitalism," "69 then media and digital arts might offer ways to excavate new arrangements of our sociotechnical system, which are never fully determined.

\section{ACKNOWLEDGEMENTS}

I am grateful for the insightful feedback from Viet Thanh Nguyen, Tara McPherson, Nayan Shah, John Carlos Rowe, Heidi Hong, Keva Bui, and Sam Ikehara. This article has greatly benefited from the guidance of special issue editor Megan Driscoll and an anonymous reviewer. In addition, I thank the archivists at the Nam June Paik Archive, especially Hannah Pacious, for their research assistance and company. All faults in this essay are my own.

\section{ENDNOTES}

1 “Orientals Find Bias Is Down Sharply in the U.S.," New York Times, December 13, 1970, https:/www.nytimes.com/1970/12/13/archives/orientals-find-bias-is-down-sharply-in-usdiscrimination-against.html.

${ }^{2}$ Ibid.

${ }^{3} \mathrm{I}$ bid.

${ }^{4}$ For a comprehensive cultural history of "yellow peril," see John Kuo, Wei Tchen, and Dylan Yeats, Yellow Peril!: An Archive of Anti-Asian Fear (New York: Verso Books, 2014).

5 "Orientals."

${ }^{6}$ N. Katherine Hayles, How We Became Posthuman: Virtual Bodies in Cybernetics, Literature, and Informatics (Chicago: University of Chicago Press), 13.

${ }^{7}$ Colleen Lye, America's Asia: Racial Form and American Literature, 1893-1945 (Princeton: Princeton University Press, 2005), 11. 
${ }^{8}$ Joseph Jeon, Racial Things, Racial Forms: Objecthood in Avant-Grade Asian American Poetry (Iowa City: University of Iowa Press, 2012), xxv.

${ }^{9}$ In this article, I will be extending Alexander Galloway's framing of the interface not as a technological artifact but as an "effect," a visual form of complex historical processes. Alexander Galloway, The Interface Effect (New York: Polity, 2012), 67.

${ }^{10}$ Michelle Yun, "Nam June Paik: Evolution, Revolution, Resolution," in Nam June Paik: Becoming Robot, ed. Melissa Chiu and Michelle Yun (New York: Asia Society Museum, 2014), 18.

${ }^{11}$ Galloway, 33.

${ }^{12}$ Ibid., viii.

${ }^{13}$ Nam June Paik, "Tribute to John Cage," Nam June Paik Paper Archives, Washington, DC, Box 7, Folder 9.

${ }^{14}$ Gregory Zinman, "Nam June Paik's Etude 1 and the Indeterminate Origins of Digital Media Art," October 164 (2018): 18.

${ }^{15}$ Jussi Parikka, What Is Media Archaeology? (Cambridge: Polity Press, 2012), 152.

16 "Orientals."

${ }^{17}$ Ibid.

${ }^{18}$ Norbert Weiner, The Human Use of Human Beings (Boston: Houghton Mifflin Harcourt, 1950), 33.

${ }^{19}$ Orit Halpern, Beautiful Data: A History of Vision and Reason since 1945 (Durham: Duke University Press, 2015), 60.

${ }^{20}$ David Joselit, "Tale of the Tape: Radical Software," Artforum 40, no. 9 (2002): 155.

${ }^{21}$ Nam June Paik, "Unidentified Transcripts," Nam June Paik Paper Archives, Washington, DC, Box 14, Folder 27.

${ }^{22}$ Ibid.

${ }^{23}$ Steve F. Anderson, Technologies of History: Visual Media and the Eccentricity of the Past (Chicago: University of Chicago Press, 2011), 9.

${ }^{24}$ Paik, "Unidentified Transcripts."

${ }^{25}$ Lye, 9.

${ }^{26}$ Paik partnered with Japanese video engineer Shuye Abe to invent the Paik-Abe synthesizer. The device receives images from seven cameras and then distorts and colorizes the imagery. Through signal manipulation, the synthesizer distorts the input to produce a prismatic, surrealist video or image. For a detailed description, see Michelle Yun, "Nam June Paik: Evolution, Revolution, Resolution," in Becoming Robot, ed. Melissa Chiu and Michelle Yun (New Haven: Yale University Press, 2014), 47-52.

${ }^{27}$ Wendy Hui Kyong Chun, "Race and/as Technology; or, How to Do Things to Race," Camera Obscura 24, no. 1 (2009): 39.

${ }^{28}$ Yun, 15.

${ }^{29}$ Jodi Melamed, Represent and Destroy: Rationalizing Violence in the New Racial Capitalism (Minneapolis: University of Minnesota Press, 2011), 2.

${ }^{30}$ Ellen Wu, The Color of Success: Asian Americans and the Origins of the Model Minority (Princeton: Princeton University Press, 2013).

${ }^{31}$ William Peterson, "Success Story, Japanese-American Style," New York Times, January 9, 1966, https://www.nytimes.com/1966/01/09/archives/success-story-japaneseamerican-stylesuccess-story-japaneseamerican.html. Emphasis mine.

${ }^{32}$ Celebrated by the company founded by Gordon Moore, Intel, Moore's Law is still embraced as the prevailing imaginary of technological development. "Over 50 Years of Moore's Law," Intel, 
accessed Dec 2, 2020, https://www.intel.com/content/www/us/en/silicon-innovations/mooreslaw-technology.html.

${ }^{33}$ Wendy Hui Kyong Chun, Programmed Visions: Software and Memory (Cambridge: MIT Press, 2011), 18.

${ }^{34}$ Galloway, 44.

${ }^{35}$ For a detailed history of SAGE's relationship to the modern user interface, see Cliff Kuang and Robert Fabricant's genealogy of the modern user interface. Cliff Kuang and Robert Fabricant, User Friendly: How the Hidden Rules of Design Are Changing the Way We Live, Work, and Play (New York: MacMillan Publishers, 2019), 127-158.

${ }^{36}$ The influence of Engelbart's GUI and oN-Line system on the contemporary computer interface is a point of debate for computer historians, who sometimes highlight other actors, institutions, and events that contributed to the GUI's realization. My aim here is not to conclusively credit Engelbart with the GUI but rather to point to the technological visions that have orbited around Engelbart, his "Mother of All Demos," the oN-Line system, and bootstrapping. All of this illustrates the nascent imaginary of the interface forming in the late 1960s and, no doubt, developed further in the later decades in the era of personal computing.

${ }^{37}$ Kuang and Fabricant, 309.

${ }^{38}$ Full coverage of Doug Engelbart's "The Mother of All Demos" (1968) can be found in an online video and text archive at the Doug Engelbart Institute. "Doug's Great Demo: 1968," Doug Engelbart Institute, accessed January 25, 2020,

https://www.dougengelbart.org/content/view/209/448/.

${ }^{39}$ Peterson. Emphasis mine.

${ }^{40}$ Chun, Programmed Visions, 6.

${ }^{41}$ Thierry Bardini, Bootstrapping: Douglas Engelbart, Coevolution, and the Origins of Personal Computing (Stanford: Stanford University Press, 2000).

${ }^{42}$ Competing technological imaginaries accompanied the development of new digital and computational technologies. Kuang and Fabricant show how Engelbart's ideas differed from those of other leading technologists, such as computer scientist and artificial intelligence pioneer Marvin Minsky. They write, "On the one side, Minsky imagined what the machine could become as something outside ourselves, perhaps beyond us. Engelbart, instead, saw machines as tools built to serve." Kuang and Fabricant, 313.

${ }^{43}$ In many ways, Engelbart's technological media philosophy aligned with Marshall McLuhan's understanding of media as extensions of human faculties and sensoria. Marshall McLuhan, The Medium Is the Massage: An Inventory of Effects (New York: Bantam Books, 1967), 26.

${ }^{44}$ Peterson.

${ }^{45}$ Tara McPherson, "U.S Operating Systems at Mid-Century: The Intertwining of Race and UNIX," in Race After the Internet, ed. Lisa Nakamura and Peter Chow-White (Cambridge: MIT Press, 2012), 24.

46 "Orientals."

${ }^{47}$ To learn more about the specific ways model minority discourse was used as a racial strategy for managing social uprisings, See $\mathrm{Wu}$.

${ }^{48}$ Paul Ong and John M. Liu, "U.S. Immigration Policies and Asian Migration," in The New Asian Immigration in Los Angeles and Global Restructuring, ed. Paul Ong, Edna Bonacich, and Lucie Cheng (Philadelphia: Temple University Press, 1994), 58.

49 “Obituary," Jeffrey Chuan Chu, accessed Dec. 18, 2020, https://tsaifamily.org/chuan/.

${ }^{50}$ My thinking on the STEM-driven economic conditions of Asian/American subjectivity and racialization is informed by Christopher Fan's analysis of post-1965 Asian/American literature. 
Christopher T. Fan, "Science Fictionality and Post-65 Asian American Literature," American Literary History (Oxford: Oxford University Press, 2020).

${ }^{51}$ Margaret Rhee has written an informative article about Paik's artistic inquiries into Asian racialization. Teasing out the conflation between the Asian and the robot, Rhee suggests that Paik was invested in racial critique through his creative tinkering. Margaret Rhee, "Racial Recalibration: Nam June Paik's K-456," Asian Diasporic Visual Cultures and the Americas 1 (2015): 285-309.

${ }^{52}$ McPherson, 24.

${ }^{53}$ Wendy Hui Kyong Chun, "On Software, or the Persistence of Visual Knowledge," Grey Room 18 (2004): 26-51.

${ }^{54}$ Zinman, 4.

${ }^{55}$ Paik entered Bell Labs under the guidance of Bell Labs engineers such as A. Michael Knoll, although Paik mostly experimented on his own. Paik, letter from M.V. Mathews, November 23, 1966, Nam June Paik Paper Archives, Washington, DC, Box 7, Folder 7.

${ }^{56}$ For a thorough history of Bell Labs, see Jon Gertner, The Idea Factory: Bell Labs and the Great Age of American Innovation (New York: Penguin Random House, 2012).

${ }^{57}$ There were many scientists and engineers at Bell Labs who were themselves artists. Early digital art at Bell Labs includes the work of A. Michael Noll, Leon Harmon, and Kenneth C. Knowlton, who worked on software and computer art projects individually and collaboratively.

${ }^{58}$ Nam June Paik, "Untitled Essay,” November 30, 1966, Nam June Paik Paper Archives, Smithsonian American Art Museum, Washington, DC, Box 12, Folder 14.

${ }^{59}$ In a sense, Paik's Confused Rain is a predecessor of the more commonly known visual of "code rain" popularized by The Matrix. As a characteristic marker of the franchise, the green Matrix digital code (which, interestingly enough, combines both Japanese and Western Latin typography) represents both the immersion and glitch of a virtual reality environment.

${ }^{60}$ William Kaizen, "Computer Participator: Situating Nam June Paik's Work in Computing," Mainframe Experimentalism: Early Computing and the Foundations of the Digital Arts, ed. Hannah B. Higgins and Douglas Kahn (Berkeley: University of California Press, 2012), 231. ${ }^{61}$ Nam June Paik, Videa 'n' Videology 1959-1973 (Syracuse, NY: Everson Museum of Art, 1997), 42.

${ }^{62}$ Kandice Chuh, “It's Not About Anything," Social Text 32, no. 4 (2014): 130.

${ }^{63}$ Ibid., 131.

${ }^{64}$ McPherson, 24.

${ }^{65}$ Nam June Paik, "For a Deer," in Charles Hirsch, Het Binaire Tijdperk: Nieuwe Interacties, (Ghent, Belgium: Ludion, 1992). Quoted in Zinman.

66 "Orientals." Emphasis mine.

${ }^{67}$ Peterson. Emphasis mine.

${ }^{68}$ Paik, "For a Deer."

${ }^{69}$ Neda Atanasoski and Kalindi Vora, Surrogate Humanity: Race, Robots, and the Politics of Technological Futures (Durham: Duke University Press, 2019), 4.

\section{REFERENCES}

Anderson, Steven F. Technologies of History: Visual Media and the Eccentricity of the Past. Chicago: University of Chicago Press, 2011.

Atanasoski, Neda and Kalindi Vora. Surrogate Humanity: Race, Robots, and the Politics of 
Technological Futures. Durham: Duke University Press, 2019.

Bardini, Thierry. Bootstrapping: Douglas Engelbart, Coevolution, and the Origins of Personal Computing. Stanford: Stanford University Press, 2000.

Chiu, Melissa and Michelle Yun. Nam June Paik: Becoming Robot. New Haven: Yale University Press, 2014.

Chuh, Kandice. "It's Not About Anything." Social Text 32, no. 4 (2014): 125-134.

Chun, Wendy Hui Kyong. "On Software, or the Persistence of Visual Knowledge." Grey Room 18 (2004): 26-51.

Programmed Visions: Software and Memory. Cambridge: MIT Press, 2011.

- "Race and/as Technology; or, How to Do Things to Race." In Race After the Internet, edited by Lisa Nakamura and Peter Chow-White, 38-60. Cambridge, MA: MIT Press, 2012.

“Doug's Great Demo: 1968.” Doug Engelbart Institute. Accessed Jan. 25, 2020. https://www.dougengelbart.org/content/view/209/448/.

Fan, Christopher T. "Science Fictionality and Post-65 Asian American Literature." American Literary History 33, no. 1 (2021): 75-102.

Galloway, Alexander R. The Interface Effect. New York: Polity, 2012.

Gertner, Jon. The Idea Factory: Bell Labs and the Great Age of American Innovation. New York: Penguin Random House, 2012.

Halpern, Orit. Beautiful Data: A History of Vision and Reason since 1945. Durham: Duke University Press, 2015.

Hanhardt, John G. "Nam June Paik." Artforum 44, no. 2 (2006).

https://www.artforum.com/print/200604/nam-june-paik-10623.

Hayles, N. Katherine. How We Became Posthuman: Virtual Bodies in Cybernetics, Literature, and Informatics. Chicago: University of Chicago Press.

Jeon, Joseph. Racial Things, Racial Forms: Objecthood in Avant-Grade Asian American Poetry. Iowa City: University of Iowa Press, 2012.

Joselit, David. “Tale of the Tape: Radical Software.” Artforum 4, no. 9 (2002): 155-96.

Kaizen, William. “Computer Participator: Situating Nam June Paik's Work in Computing.” In Mainframe Experimentalism: Early Computing and the Foundations of the Digital Arts, edited by Hannah B. Higgins and Douglas Kahn, 229-39. Berkeley: University of California Press, 2012. 
Kuang, Cliff, and Robert Fabricant. User Friendly: How the Hidden Rules of Design are Changing the Way We Live, Work, and Play. New York, NY: MacMillan Publishers, 2019.

Lye, Colleen. America's Asia: Racial Form and American Literature, 1893-1945. Princeton: Princeton University Press, 2005.

McLuhan, Marshall. The Medium is the Massage: An Inventory of Effects. New York: Bantam Books, 1967.

McPherson, Tara. "U.S Operating Systems at Mid-Century: The Intertwining of Race and UNIX." In Race After the Internet, edited by Lisa Nakamura and Peter Chow-White, 2137. Cambridge, MA: MIT Press, 2012.

Melamed, Jodi. Represent and Destroy: Rationalizing Violence in the New Racial Capitalism. Minneapolis: University of Minnesota Press, 2011.

“Obituary.” Jeffrey Chuan Chu. Accessed December 18, 2020. https://tsaifamily.org/chuan/.

Ong, Paul and John M. Liu. "U.S. Immigration Policies and Asian Migration." In The New Asian Immigration in Los Angeles and Global Restructuring, edited by Paul Ong, Edna Bonacich, and Lucie Cheng. Philadelphia: Temple University Press, 1994.

“Orientals Find Bias Is Down Sharply in the U.S." New York Times. December 13, 1970. https:/www.nytimes.com/1970/12/13/archives/orientals-find-bias-is-down-sharply-in-usdiscrimination-against.html.

“Over 50 Years of Moore's Law.” Intel. Accessed December 2, 2020.

https://www.intel.com/content/www/us/en/silicon-innovations/moores-lawtechnology.html.

Paik, Nam June. "For a Deer." In Charles Hirsch, Het Binaire Tijdperk: Nieuwe Interacties. Ghent, Belgium: Ludion, 1992.

_. Videa 'n'Videology 1959-1973. Syracuse, NY: Everson Museum of Art, 1997.

_. "Paik, "Yellow Peril! (1963-1964)." Medie Kunst Netz. Accessed August 1, 2021. http://www.medienkunstnetz.de/works/yellow-peril/.

"Dine at Rainbow." Nam June Paik Paper Archives, Smithsonian American Art Museum, Washington, DC, Box 13, Folder 29.

Letter from M.V. Mathews. Nov. 23, 1966. Nam June Paik Paper Archives, Smithsonian American Art Museum, Washington, DC, Box 7, Folder 7. 
. “Tribute to John Cage," Nam June Paik Paper Archives, Smithsonian American Art Museum, Washington, DC, Box 7, Folder 9.

. "Unidentified Transcripts." Nam June Paik Paper Archives, Smithsonian American Art Museum, Washington, DC, Box 14, Folder 27.

. "Untitled Essay." November 30, 1966. Nam June Paik Paper Archives. Smithsonian American Art Museum, Washington, DC, Box 12, Folder 14.

Parikka, Jussi. What Is Media Archaeology? Cambridge: Polity Press, 2012.

Peterson, William. “Success Story, Japanese-American Style.” New York Times. January 9, 1966. https://www.nytimes.com/1966/01/09/archives/success-story-japaneseamerican-stylesuccess-story-japaneseamerican.html.

Rhee, Margaret. “Racial Recalibration: Nam June Paik’s K-456.” Asian Diasporic Visual Cultures and the Americas 1 (2015): 285-309.

Tchen, John Kuo Wei, and Dylan Yeats. Yellow Peril!: An Archive of Anti-Asian Fear. New York: Verso Books, 2014.

Wu, Ellen. The Color of Success: Asian Americans and the Origins of the Model Minority. Princeton: Princeton University Press, 2013.

Weiner, Norbert. The Human Use of Human Beings. Boston: Houghton Mifflin Harcourt, 1950.

Yun, Michelle. "Nam June Paik: Evolution, Revolution, Resolution.” Nam June Paik: Becoming Robot, edited by Melissa Chiu and Michelle Yun. New York: Asia Society Museum, 2014.

Zinman, Gregory. "Nam June Paik's Etude 1 and the Indeterminate Origins of Digital Media Art." October 164 (2018): 3-28.

\section{AUTHOR BIO}

Huan He is a Ph.D. candidate in American Studies \& Ethnicity at the University of Southern California. Titled "The Racial Interface: Informatics and Asian/America," his dissertation explores the racial associations linking Asian/Americans and technology in the early digital era from 1942 to 1984 . His research interests also include digital game studies, visual culture, and poetics. His writing has appeared in American Quarterly, College Literature: A Journal of Critical Literary Studies, and Journal of Asian American Studies. 